\title{
Day-to-Day Variability of Low Latitude F-Region lonosphere During Low Solar Activity
}

\author{
Anju Nagar, ", Satyadeo Mishra², Surendra Kumar Vijay ${ }^{3}$ \\ ${ }^{1}$ Department of Physics, S.M.S. Govt Model Science College Gwalior Madhya Pradesh, India \\ ${ }^{2}$ Department of Physics, Govt M.L.B. PG College Bhopal Madhya Pradesh, India \\ ${ }^{3}$ Department of Physics, Institute for Excellence in Higher Education, Bhopal, India \\ Email address: \\ nagaranjugwl@rediffmail.com (A. Nagar),sdm_phy@ymail.com (S. D. Mishra),drskvijay@gmail.com (S. K. Vijay)
}

\section{To cite this article:}

Anju Nagar, Satyadeo Mishra, Surendra Kumar Vijay. Day-to-Day Variability of Low Latitude F-Region Ionosphere During Low Solar Activity. International Journal of Astrophysics and Space Science. Vol. 3, No. 3, 2015, pp. 30-41. doi: 10.11648/j.ijass.20150303.12

\begin{abstract}
This paper presents an analysis of the F-region variability of the ionospheric parameters [foF2and M(3000)F2] at three low latitude stations during low solar activity periods from January 2006 to December 2010. The diurnal, seasonal and day-to-day characteristics of theseionospheric F-region parameters have been studied in detail. With the use of partial correlation analysis we have computed the correlation between the variation of these parameters and other factors such as the solar radio flux $10.7 \mathrm{~cm}\left(\mathrm{~F}_{10.7}\right)$ and the geomagnetic $\mathrm{A}_{\mathrm{P}}$ index. It has been observed that the magnitude of the variability of propagation parameter $\mathrm{M}(3000) \mathrm{F} 2$ aresmoother and smaller than in that case of foF2. It is also observed that for both parameters there are no remarkable changes in day-to-day variability with geomagnetic activity during low solar activity.
\end{abstract}

Keywords: F-Region, Critical Frequency, IonosphericDisturbances, Variability

\section{Introduction}

The ionosphere is the ionized region of the upper atmosphere which consists of free electrons and positive ions in an electrically neutral medium. It extends from $\sim 60 \mathrm{~km}$ up to $\sim 1000 \mathrm{~km}$. The free ions are mainly formed as a result of the interaction between solar radiation and gas molecules. These free ions control the conductivity and electrical property of the medium and they are cause of reflection or bending of radio signals occurring at certain critical frequencies in the ionosphere. The critical frequency varies with the intensity of ionization. The abundance of these charged particles in the ionosphere affects the propagation

The variation of the F-region electron density distribution greatly affects the propagation of the radio waves through the ionosphere. The electron density of the F2-region of the ionosphere is reflected in the values of the critical frequency, $\mathrm{foF}_{2}$ since the critical frequency fc and the electron density are related as $\mathrm{fc}=9 \mathrm{n}^{1 / 2}$ where fc is the critical frequency and $\mathrm{n}$ the electron density. The $\mathrm{M}(3000) \mathrm{F}_{2}$ is closely related to the critical frequency of the F2- layer, fo $\mathrm{F}_{2}$ and definedas the ratio of the maximum usable frequency (MUF) at a distance of $3000 \mathrm{~km}$ to the $\mathrm{F}_{2}$-layer critical frequency

$$
M(3000) F 2=M U F(3000) F 2 / f o F 2
$$

Propagation factor is essential for planning $\mathrm{HF}$ propagation radio links and also useful for ionospheric modelling. The high variability of the ionosphere has significant effect on the $\mathrm{F}_{2}$-layer critical frequency $\left(\mathrm{foF}_{2}\right)$ and the propagation parameter $\mathrm{M}(3000) \mathrm{F}_{2}$.

The day-to-day variability in F-region parameters which is apparently unrelated to any specific solar or magnetic event is perhaps the biggest challenge for ionospheric forecasters and this problem is particularly severe in tropical latitudes. It is well known that the low latitude is a complex area of the ionosphere because it is simultaneously affected by dynamo electric fields and thermospheric winds. A most interesting characteristics feature of the low latitude ionosphere is the equatorial ionization anomaly (EIA) with maximum electron densities on either side of the magnetic equator produced by the equatorial plasma fountain effect [1-4].

More recently, a lot of attention has been directed towards understanding the dynamic behaviour of the equatorial ionosphere. Adebesin [5] investigated the variability of $F_{2}$ layer critical frequency $\left(\mathrm{foF}_{2}\right)$ over Jicamarca station along the equator anomaly trough during solar minimum period. The author reports that the night time downward reversal 
value in vertical plasma drift coincides with the enhanced foF $_{2}$ variability. Adebiyi et al. [6] focused on the GPS TEC and $\mathrm{foF}_{2}$ variability at equatorial station and showed the performance of IRI-model. Gnabahou et al. [7] have been analyzed variability of foF $_{2}$ at African equatorial stations and showed that the variability is clearly depends on the dip angle of the location. Ouattara et al. [8] studied the variability of $\mathrm{foF}_{2}$ at two West African EIA stations with solar cycle, season and time of day and made comparison between data and models. Hoque and Jakowski [9] derived an empirical $\mathrm{hmF}_{2}$ model using a large database of propagation parameters $\mathrm{M}(3000) \mathrm{F}_{2}$ and $\mathrm{hmF}_{2}$ collected through a world-wide network of 69 ground ionosondes.

Some earlier, research shows that the ionosphere is highly variable in space and time according to geographical location. Ezquer et al. [10] studied the diurnal seasonal and latitudinal behaviour of the variability of ionospheric parameters $\left(\mathrm{foF}_{2}\right.$ and $\left.\mathrm{M}(3000) \mathrm{F}_{2}\right)$ and observed low variability for propagation factor $\mathrm{M}(3000) \mathrm{F}_{2}$. Their results show that the variability parameter does not vary with modip. Bilitza et al. [11] observed seasonal differences in variability and suggested that seasonal effects seen are more likely a result of seasonal changes in the build-up of the equator anomaly crests. Lately, Al-Ubaidi [12] studied the diurnal variation of the $F_{2}$-layer critical frequency $\left(\mathrm{foF}_{2}\right)$ with daily sunspot number $(\mathrm{R})$ during low and high solar activity period for mid-latitude station. Atac et al. [13] investigated the dependence of the foF $_{2}$ variability on solar activity over different latitudes, different local times, and different seasons in order to improve model. Prasad et al. [14] analyzed the simultaneous Ionosonde data (the virtual height of the F-layer (h'f) and the critical frequency of the F2-layer ( $\mathrm{foF}_{2}$ ) over the low and mid latitude stations. They also studied the effect of geomagnetic activity of these F-region parameters.Oyekola [15] studied the local time seasonal and solar cycle variations of the $\mathrm{M}(3000) \mathrm{F}_{2}$ and compared the results with International Reference Ionosphere 2007 model prediction of $\mathrm{M}(3000) \mathrm{F}_{2}$.

The study of $\mathrm{M}(3000) \mathrm{F}_{2}$ and its variability is scanty unlike that of $\mathrm{foF}_{2}$ which has been studiedmost frequently. In the recent years, Chandra et al. [16] studied the day-to-day variability in the critical frequency of F-layer $\left(\mathrm{foF}_{2}\right)$ over Ahmedabad situated near the anomaly crest. The result shows that the variability is much more during night time than during the day and also that while the daytime deviations are of the same order during different seasons the night-time deviations are least during equinoxes. Akala et al. [17] presented the impact of diurnal seasonal and solar activity effects on the variability of ionosphere $\mathrm{foF}_{2}$ and revealed that foF $_{2}$ is more susceptible to variability during night than the daytime. Knowledge of the variation of $\mathrm{F}_{2}$-layer critical frequency $\left(\mathrm{foF}_{2}\right)$ as well as the propagation factor $\mathrm{M}(3000) \mathrm{F}_{2}$ are great importance to investigate the physical process responsible for the ionosphericbehaviour and therefore their descriptions are included in ionospheric models such as the International Reference Ionosphere (IRI).

Moreover, the understanding of the large variability of the ionosphere during quiet and disturbed times is fundamental for improved forecasting of the low latitude ionospheric weather.The ionospheric F2-regions depends very strongly on solar activity so it suffers a large and persistent day-to-day (diurnal) and seasonal variations influenced by the variation of sunspot numbers represented by solar cycle [18]. The F2layer of the ionosphere is subject to a number of influences such as solar ionizing radiation, solar wind, geomagnetic activity and neutral atmosphere electrodynamics effects [19].Several reviews cover the different aspects of the ionosphere at equatorial and low latitudes. It is well known that the electrodynamics plays an important role in the equatorial/low latitude ionosphere. The ionosphere exhibits both temporal and spatial (latitudinal) variations. The regular variations like the daily, seasonal and solar cycle variations are fairly well understood but the day to day variability, both on geomagnetic quiet and disturbed days, is yet to be completely understood.

In the present work we have examined the critical frequency of the F2-layer, $\mathrm{foF}_{2}$ as well as the propagation parameter $\mathrm{M}(3000) \mathrm{F}_{2}$ to study the day-to-day variability of ionosphere. The diurnal, seasonal and day-to-day characteristics of such ionospheric F-region parameters over three low latitude stations were studied in detail. With the use of partial correlation analyses we analyzed the correlation between the variability of these parameters and several other factors such as the solar radio flux $10.7 \mathrm{~cm}\left(\mathrm{~F}_{10.7}\right)$ and the geomagnetic Ap index.

\section{Data and Method of Analysis}

Our analysis is based on hourly daily values foF 2 and of the propagation parameter $\mathrm{M}(3000) \mathrm{F} 2$ of three low latitude stations (Table 1) obtained through the Space Physics Interactive Data Resource (SPIDR) website (http://spidr.ngdc.noaa.gov) for the years January 2006 to December 2010. The day-to-day variability of the ionosphere is defined as a specific hour of a given month/year/location by using following relation

$$
d X=(X-X m) / X m
$$

Where $X$ stands for the hourly daily value of each of the two parameters foF2 and $\mathrm{M}(3000) \mathrm{F} 2$ respectively and $\mathrm{Xm}$ for the corresponding hourly monthly median value. To analyze the variability from day-to-day we have determined decile factors (lower decile and upper decile) at each hour of each month and year at different locations.

In this study the diurnal variation in the F2-layer critical frequency (foF2) as well as in propagation parameter M(3000)F2 have been analysed with the probability of occurrence of a given level of variability. To understand the daytime and night-time variability more clearly we divided the data into four bins of local time 00-05LT, 06-11LT, 1217LT and 18-23LT. To examine the seasonal effects we grouped all data into three seasons winter, summer and equinox using the four months of data for each season [i.e. winter (November, December, January, February), summer 
(May, June, July, August) and Equinox (March, April, September, October)], changing summer for winter months for southern hemisphere stations.

In order to examine the effect of magnetic disturbances we have considered two extreme cases viz. five International most quiet(Q) days and five disturbed (D) daysfor each month during the period January 2006 to December 2010. The details of quiet and disturbed days were obtained from the World Data Center, Kyoto Japan. Furthermore, to study the control of solar and geomagnetic activity on ionospheric parameter we used $\mathrm{F}_{\mathbf{1 0 . 7}}$ and $\mathrm{A}_{\mathrm{p}}$ indices.

Table 1. List of stations used in this study

\begin{tabular}{lll}
\hline Name ofstation & GeographicLatitude & GeographicLongitude \\
\hline Jicamarca & $12^{0} \mathrm{~S}$ & $283^{0} \mathrm{E}$ \\
Kwajalein & $09^{0} \mathrm{~N}$ & $167^{0} \mathrm{E}$ \\
Madimbo & $22^{0} \mathrm{~S}$ & $031^{0} \mathrm{E}$ \\
\hline
\end{tabular}

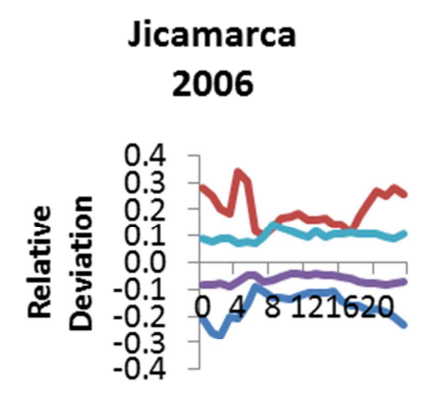
Jicamarca
2007
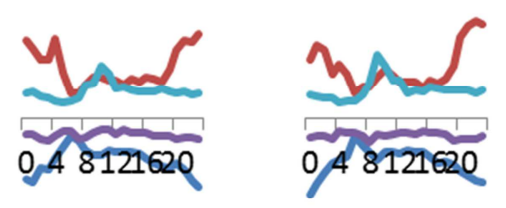
Kwajalein 2007

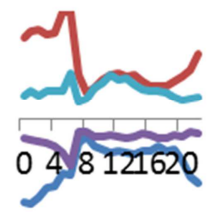

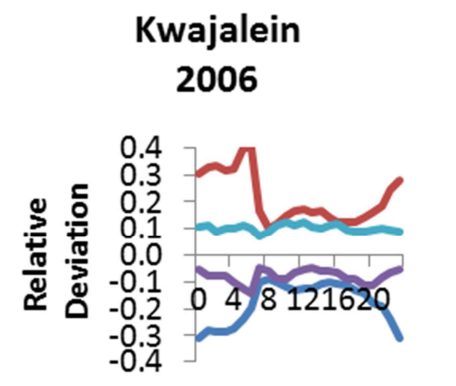
Madimbo
2006

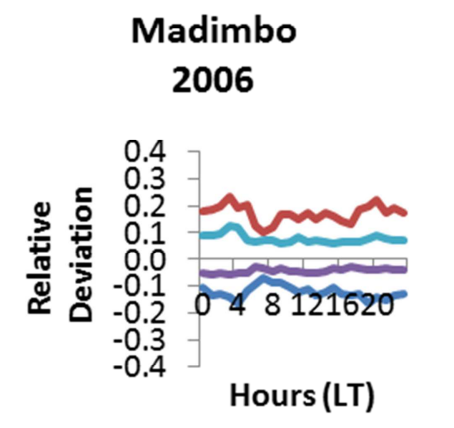

jicamarca 2008
Kwajalein 2008

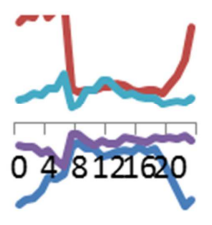
Madimbo 2008

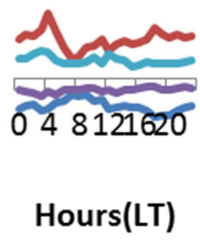

\section{Results}

\subsection{Annual Diurnal Variation of foF2 and M(3000)F2}

Fig. 1 shows the diurnal variation of yearly deciles of foF2 and $\mathrm{M}(3000) \mathrm{F} 2$ variability in terms of the local time (LT) for all three stations during the period January 2006 to December 2010. It is clear from the fig. 1 and Table 2 that the amplitude of day to day variability for the $90 \%$ of time can reach values positive or negative up to more than $40 \%$ over or (less) the corresponding monthly median at all stations during the period from January 2006 to December 2010.There are also values of relative deviations high as much as .8 and even higher and usually present after midnight up to early morning. On a station to station comparison, foF2 variability is noted to decrease for the station Madimbo situated just outside the equatorial crests. With reference to the propagationfactor $\mathrm{M}(3000) \mathrm{F} 2$ the variation ofrelative deviations are smoother and smaller than in case of foF 2 . The pattern ofthe variability of M(3000)F2 does not show any clear dependence on hour.

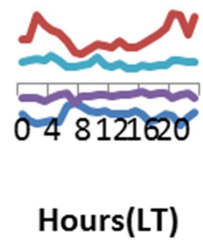
Madimbo 2007

Id [foF2]

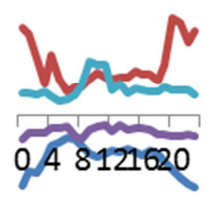
Kwajalein 2009

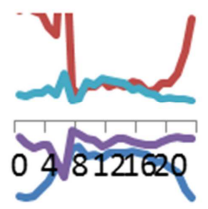
Madimbo 2009

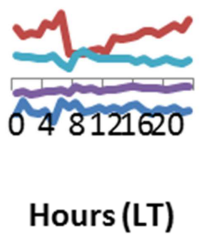

Jicamarca 2010

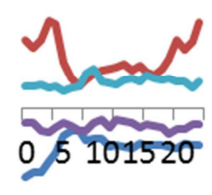

Kwajalein 2010

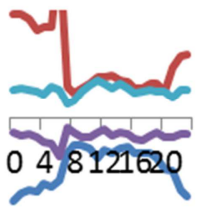

Madimbo
2010

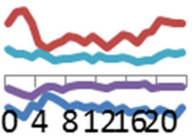

Hours(LT)

Figure 1. Diurnal variation of lower and upper deciles of deviations of foF 2 and M(3000)F2 at three locations during the period 2006 to 2010 respectively. 
Table 2. Average values of bounds (in absolute value) during day and night time at different locations and years.

\begin{tabular}{lllll}
\hline Years & Time & Jicamarca & Kwajalein & Madimbo \\
\hline \multirow{2}{*}{2006} & Day & 0.13 & 0.14 & 0.13 \\
& Night & 0.17 & 0.25 & 0.17 \\
\multirow{2}{*}{2007} & Day & 0.13 & 0.14 & 0.12 \\
& Night & 0.22 & 0.24 & 0.17 \\
\multirow{2}{*}{2009} & Day & 0.13 & 0.13 & 0.11 \\
& Night & 0.22 & 0.27 & 0.14 \\
& Day & 0.13 & 0.16 & 0.12 \\
& Night & 0.22 & 0.26 & 0.15 \\
& Day & 0.13 & 0.15 & 0.12 \\
& Night & 0.21 & 0.25 & 0.16 \\
\hline
\end{tabular}

Jicamarca

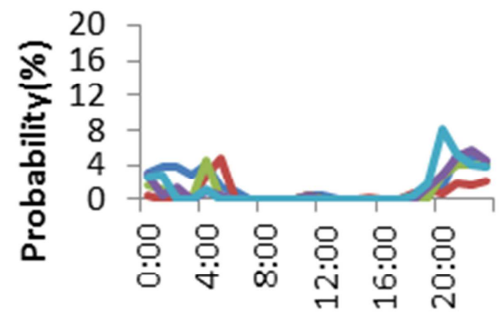

Jicamarca

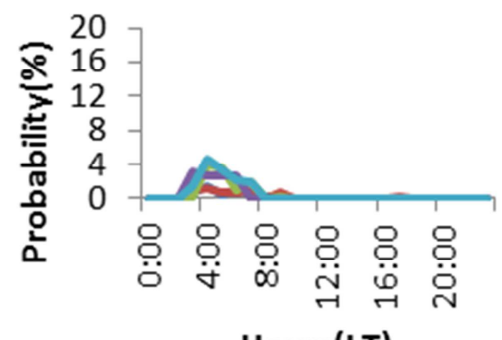

Hours(LT)
Kwajalein

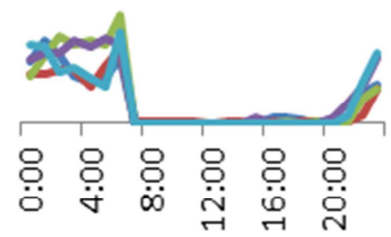

Kwajalein

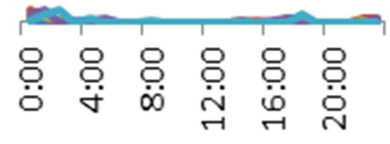

Hours(LT)
Furthermore, fig. 2 shows the levels .50 (in absolute value) of foF2 and M(3000)F2 variability are exceeded during the period 2006-2010 at different locations. It is evident that the disturbed state occurs mostly in nighttime hours and that variability depends on the solar activity and the location. At all three locations, investigations highlight that the variability of foF2 exhibit its higher values monthly during night time hours when disturbed condition usually prevail. It is also evident that in case of M(3000)F2 the disturbed stateoccurs rarely and almost independent of time of day.

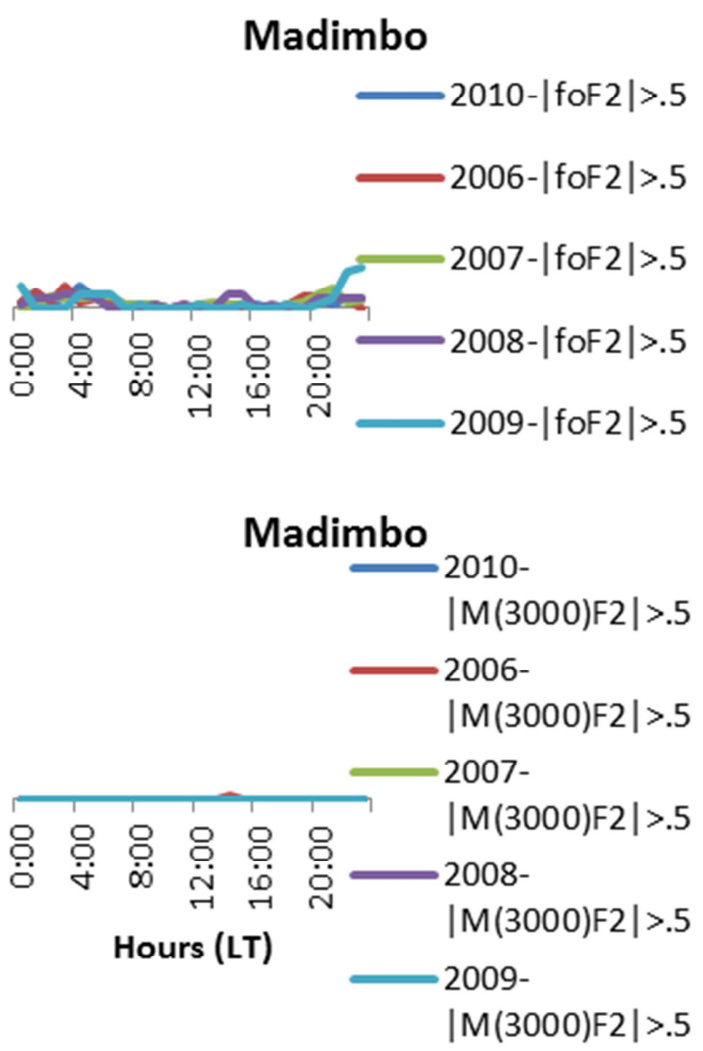

Figure 2. Hourly probability that the levels .50 of the relative deviation (in absolute value) of foF 2 and M(3000)F2 are exceeded during the period2006-2010 overthree low latitude stations.

\subsection{Annual Variation in Different Bins of Local Time of foF2 and M(3000)F2}

To find out, if high variabilityis the case of nighttime, deciles of foF 2 and M(3000)F2 variability are calculated in four bins of local time for three low latitude stations Jicamarca ,Kwajalein and Madimboover theyearsJanuary 2006 to December 2010. It is found that the bounds of variability offoF2 for time bins 6-11LT and 12-17LT are on average .12(in absolute value) over Jicamarca while they are .21 for time bins $0-5 \mathrm{LT}$ and 18-23LT during the years from January 2006 to December 2010.In case of Kwajalein the bounds of variability for time bins 6-11LT and 1217LTare on average .17 (in absolute value) while they are .24 for time bins 0-5LT and 18-23LT. Further the bounds of variability in absolute value are .10 for the daytime bins 611LT and 12-17 LT and .14 for night-time bins 0-5LT and 1823 LT over Madimbo. In general the variability is higher during night-time according to locations and Years (Table 3). 
Table 3. Average values over the day hours and over the night hours of the upper and lower deciles determined from the daily hourly data for foF 2 at the three locations during the period 2006-2010

\begin{tabular}{|c|c|c|c|c|c|c|c|c|c|c|c|c|c|}
\hline Stations & & $\mathbf{J}$ & $\mathbf{F}$ & M & $\mathbf{A}$ & M & $\mathbf{J}$ & $\mathbf{J}$ & $\mathbf{A}$ & $\mathbf{S}$ & $\mathbf{O}$ & $\mathbf{N}$ & D \\
\hline \multirow{7}{*}{ Jicamaca } & Day & & & & & & & & & & & & \\
\hline & UD & 0.14 & 0.13 & 0.13 & 0.14 & 0.14 & 0.14 & 0.14 & 0.15 & 0.14 & 0.14 & 0.14 & 0.12 \\
\hline & LD & -0.14 & -0.14 & -0.12 & -0.11 & -0.13 & -0.12 & -0.12 & -0.13 & -0.12 & -0.12 & -0.13 & -0.13 \\
\hline & Night & & & & & & & & & & & & \\
\hline & UD & 0.23 & 0.26 & 0.24 & 0.26 & 0.26 & 0.24 & 0.23 & 0.23 & 0.29 & 0.24 & 0.25 & 0.23 \\
\hline & LD & -0.20 & -0.22 & -0.20 & -0.19 & -0.19 & -0.20 & -0.17 & -0.19 & -0.16 & -0.19 & -0.20 & -0.19 \\
\hline & Day & & & & & & & & & & & & \\
\hline \multirow{5}{*}{ Kwajalein } & UD & 0.16 & 0.16 & 0.16 & 0.17 & 0.17 & 0.14 & 0.17 & 0.20 & 0.16 & 0.14 & 0.14 & 0.26 \\
\hline & LD & -0.12 & -0.13 & -0.12 & -0.11 & -0.12 & -0.14 & -0.13 & -0.13 & -0.12 & -0.10 & -0.11 & -0.11 \\
\hline & Night & & & & & & & & & & & & \\
\hline & UD & 0.28 & 0.27 & 0.25 & 0.25 & 0.29 & 0.28 & 0.28 & 0.27 & 0.29 & 0.25 & 0.27 & 0.25 \\
\hline & LD & -0.25 & -0.25 & -0.23 & -0.23 & -0.24 & -0.23 & -0.21 & -0.21 & -0.27 & -0.22 & -0.23 & -0.22 \\
\hline \multirow{6}{*}{ Madimbo } & Day & & & & & & & & & & & & \\
\hline & UD & 0.15 & 0.14 & 0.11 & 0.15 & 0.15 & 0.15 & 0.13 & 0.11 & 0.13 & 0.13 & 0.15 & 0.14 \\
\hline & LD & -0.12 & -0.10 & -0.10 & -0.09 & -0.09 & -0.09 & -0.09 & -0.08 & -0.09 & -0.10 & -0.16 & -0.12 \\
\hline & Night & & & & & & & & & & & & \\
\hline & UD & 0.22 & 0.22 & 0.17 & 0.20 & 0.17 & 0.19 & 0.22 & 0.17 & 0.18 & 0.18 & 0.22 & 0.18 \\
\hline & LD & -0.14 & -0.14 & -0.12 & -0.12 & -0.12 & -0.11 & -0.11 & -0.11 & -0.12 & -0.12 & -0.14 & -0.13 \\
\hline
\end{tabular}

On the other hand, for propagation parameter $\mathrm{M}(3000) \mathrm{F} 2$ the bounds of variability for time bins $0-5 \mathrm{LT}$ and $12-17 \mathrm{LT}$ are .07 (in absolute value) on average over Jicamarca while they are .08 for time bins 6-11LT and 18-23 LT during the years from January 2006 to December 2010. Over Kwajalein the bounds of variability on average are .09 (in absolute value) for time bins $0-5 \mathrm{LT}, 6-11 \mathrm{LT}$ and 12-17LT while they are .07 for time bins 18-23 LT. In case of Madimbo the bounds of variability on average are .06 for time bins $0-5 \mathrm{LT}$ whereas they are .04 for time bins 6-11LT and 12-17LT and 18-23 LT. Also, it has been pointed out that the upper deciles (positive variability)of the propagation factor $\mathrm{M}(3000) \mathrm{F} 2$ have clear dependence on hour rather than lower deciles (negative variability) [Table 4].

Table 4. Average values over the day hours and over the night hours of the upper and lower deciles determined from the daily hourly data for M(3000)F2 at the three locations during the period 2006-2010

\begin{tabular}{|c|c|c|c|c|c|c|c|c|c|c|c|c|c|}
\hline Stations & & $\mathbf{J}$ & $\mathbf{F}$ & M & A & M & $\mathbf{J}$ & $\mathbf{J}$ & A & $\mathbf{S}$ & $\mathbf{O}$ & $\mathbf{N}$ & D \\
\hline \multirow{6}{*}{ Jicamaca } & Day & & & & & & & & & & & & \\
\hline & UD & 0.12 & 0.11 & 0.09 & 0.09 & 0.09 & 0.13 & 0.14 & 0.17 & 0.12 & 0.10 & 0.11 & 0.11 \\
\hline & LD & -0.07 & -0.05 & -0.05 & -0.05 & -0.06 & -0.06 & -0.06 & -0.06 & -0.04 & -0.04 & -0.06 & -0.06 \\
\hline & Night & & & & & & & & & & & & \\
\hline & UD & 0.12 & 0.10 & 0.09 & 0.09 & 0.08 & 0.08 & 0.07 & 0.08 & 0.07 & 0.09 & 0.11 & 0.10 \\
\hline & LD & -0.11 & -0.08 & -0.06 & -0.06 & -0.07 & -0.07 & -0.06 & -0.07 & -0.06 & -0.06 & -0.07 & -0.09 \\
\hline \multirow{6}{*}{ Kwajalein } & Day & & & & & & & & & & & & \\
\hline & UD & 0.12 & 0.11 & 0.10 & 0.09 & 0.12 & 0.14 & 0.17 & 0.15 & 0.13 & 0.10 & 0.09 & 0.10 \\
\hline & LD & -0.09 & -0.07 & -0.06 & -0.06 & -0.07 & -0.08 & -0.10 & -0.08 & -0.08 & -0.06 & -0.06 & -0.08 \\
\hline & Night & & & & & & & & & & & & \\
\hline & UD & 0.09 & 0.08 & 0.09 & 0.10 & 0.12 & 0.12 & 0.11 & 0.11 & 0.10 & 0.08 & 0.08 & 0.08 \\
\hline & LD & -0.09 & -0.07 & -0.06 & -0.08 & -0.08 & -0.08 & -0.09 & -0.09 & -0.09 & -0.07 & -0.06 & -0.09 \\
\hline \multirow{6}{*}{ Madimbo } & Day & & & & & & & & & & & & \\
\hline & UD & 0.08 & 0.08 & 0.05 & 0.06 & 0.07 & 0.07 & 0.08 & 0.07 & 0.07 & 0.06 & 0.08 & 0.08 \\
\hline & LD & -0.04 & -0.04 & -0.03 & -0.03 & -0.04 & -0.06 & -0.06 & -0.04 & -0.04 & -0.04 & -0.03 & -0.03 \\
\hline & Night & & & & & & & & & & & & \\
\hline & UD & 0.09 & 0.09 & 0.07 & 0.09 & 0.08 & 0.09 & 0.10 & 0.08 & 0.08 & 0.07 & 0.07 & 0.07 \\
\hline & LD & -0.04 & -0.04 & -0.03 & -0.04 & -0.05 & -0.07 & -0.07 & -0.05 & -0.04 & -0.04 & -0.03 & -0.04 \\
\hline
\end{tabular}

\subsection{Seasonal Variation of foF 2 and $M(3000) F 2$}

In order to understand seasonal variations deciles of foF2 and $\mathrm{M}(3000) \mathrm{F} 2$ variabilityarecomputed for three seasons winter, summer and equinox. It is observed that over Jicamarca the upper and lower limits of variability are highest for the months summer and winterhave an average value .17 (in absolute value) at 11-12 LT and 9 LT respectively while they are highest with value .30 for summer months during nighttime. For the station Kwajalein, it is found that the bounds in 
absolute value are maximum for winter months have an average value .44 (in absolute value) during day time at 6 LT while they aremaximum for summer seasons having value .38 during night time. Further over the stationMadimbo the bounds of variability are highest for winter months during daytime have an average value .17 (in absolute value) while they are maximum for summer months have an average value .20 during night time.Also, it is found thatthe bounds of variability of propagation parameter $\mathrm{M}(3000) \mathrm{F} 2$ does not show substantial seasonal variation for any stations. Altogether, it can be concluded that no substantial seasonal variations are found either in foF2 or in M(3000)F2.

Further on the basis of monthly median values of hourly

Jicamaraca
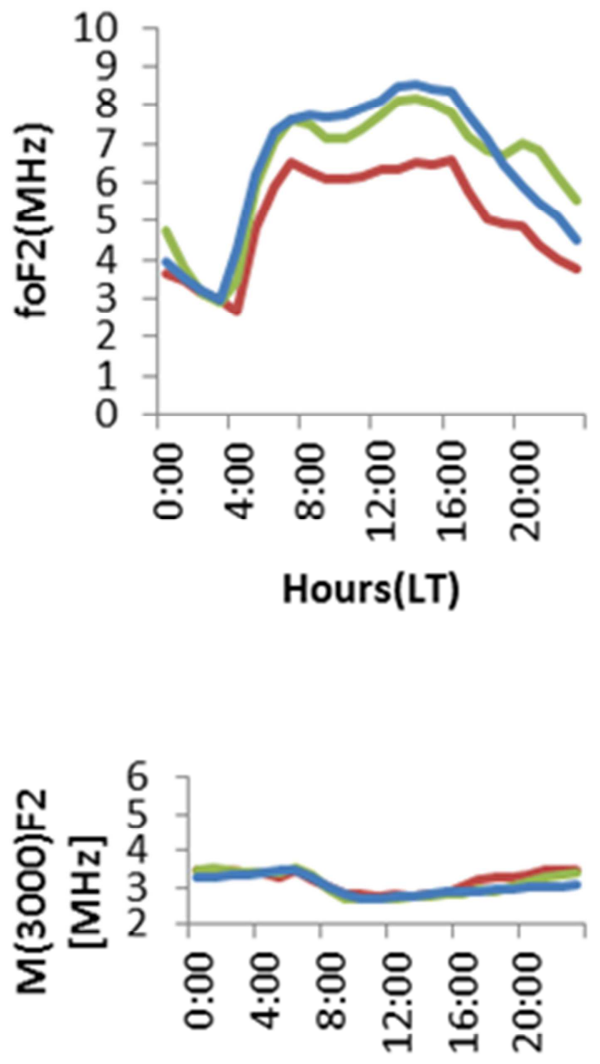

Hours (LT)

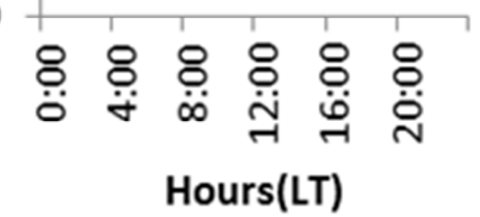

Hours(LT)
Kwajalein
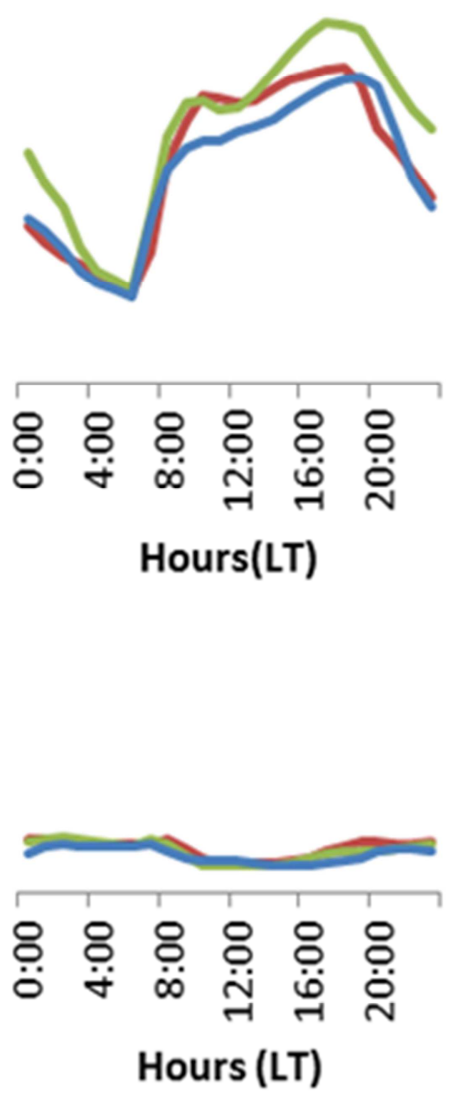

Madimbo

data of both parameters mean diurnal variations have been derived for different seasons during the period 2006-2010 separately. These results are presented in fig. 3. Fig. 3 illustrates that the winter anomaly is slightly presented in northern hemisphere and totally absent in southern hemisphere. It is clearly indicated that the winter anomaly decays in amplitude or not present with decreasing solar activity. Furthermore, during winter and equinox months a clear frequent noon-time bite outs are observed at the station Kwajalein. The analysis of the fig. 3 (lower panel) indicates that the diurnal and seasonal behaviour of propagation parameter M(3000)F2 is quite opposite to that of foF2. 
and disturbed days are shown in fig. 4 as a function of local time. It is foundthat for quiet days the upper and lower limits offoF2 variability are .15 (in absolute value) on average over jicamarcaduring the daytimebut they are .23 during night time whereas for disturbed days they become .17 during daytime and .25 during night. At Kwajalein the bounds of variability for quiet days are on average .16 (in absolute value) duringday time but they become higher reaching an average value .28 for night time conditions while for disturbed days the bounds of variability are .18 and .31duringdaytimeandnight-time respectively.Further, in case of Madimbo the upper and lower limits of foF2 in
Kwajalein(Q-Days)

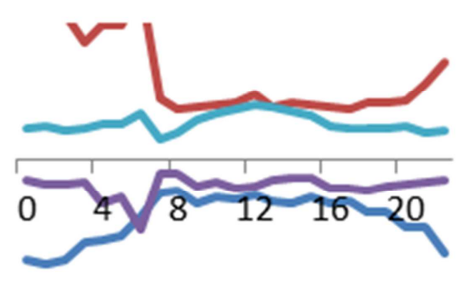

Kwajalein(D-Days)

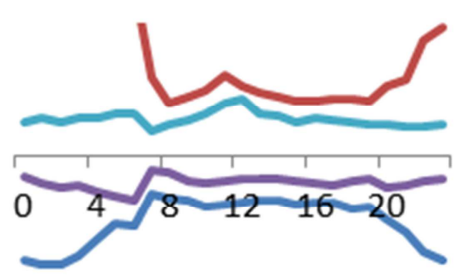

Hours (LT)
Madimbo(Q-Days)

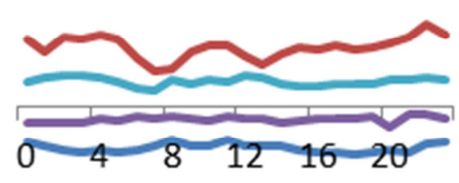

Madimbo (D-Days)

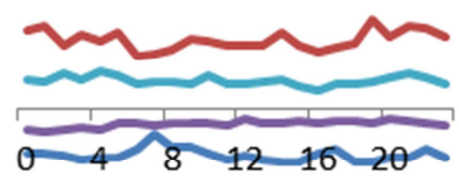

Hours(LT) $\longrightarrow$ Id [foF2] ud [foF2] $\longrightarrow$ Id [M(3000)F2 ud [M(3000)F2]

Figure 4. Diurnal variation of deciles of foF 2 and M(3000)F2 variability for quiet and disturbed days for the period of $2006-2010$.

\subsection{Solar and Geomagnetic Control of foF2 and $M(3000) F 2$}

To investigate the geomagnetic and solar control on the monthly variation of ionospheric parameters foF2 and $\mathrm{M}(3000) \mathrm{F} 2$ correlation analysis have been presented in fig. 5 to fig. 6 respectively. The straight lines are simple linear regression lines and the included values are partial correlation coefficients.In fig. 5 the upper and lower deciles (ud\% and $\mathrm{ld} \%$ ) and decile differences (dp\%) ofthe monthly foF2 values are presented in dependence on the geomagnetic activity index $A_{p}$ andsolar activity index $F_{10.7}$ for all values during 2006 until 2010 forthestation Jicamarca. It is clear that partial correlation coefficients $\mathrm{r}\left(\mathrm{ld}, \mathrm{F}_{10.7}\right.$ and $\left.\mathrm{A}_{\mathrm{p}}\right) \mathrm{r}\left(\mathrm{ud}, \mathrm{F}_{10.7}\right.$ and $\left.A_{p}\right)$ and $r\left(d p, F_{10.7}\right.$ and $\left.A_{p}\right)$ are generally higher with their corresponding coefficients $\mathrm{r}\left(\mathrm{ld}, \mathrm{A}_{\mathrm{p}}\right.$ and $\left.\mathrm{F}_{10.7}\right), \mathrm{r}\left(\mathrm{ud}, \mathrm{A}_{\mathrm{p}}\right.$ and $\left.\mathrm{F}_{10.7}\right)$ andr(dp, $A_{p}$ and $\left.F_{10.7}\right)$. The influence of solar activity on the monthly variation of foF2 is however, be small.

In fig. 6 the upper and lower deciles ( $\mathrm{ud} \%$ and $\mathrm{ld} \%$ ) and decile differences (dp\%) ofthe monthly M(3000)F2 values are presented in dependence on the geomagnetic activity index $A_{p}$ andsolar activity index $F_{10.7}$ for all values during 2006 until 2010 forthestationJicamarca. It is clear that partial correlation coefficients $\mathrm{r}\left(\mathrm{ld}, \mathrm{F}_{10.7}\right.$ and $\left.\mathrm{A}_{\mathrm{p}}\right), \mathrm{r}\left(\mathrm{ud}, \mathrm{F}_{10.7}\right.$ and $\left.\mathrm{A}_{\mathrm{p}}\right)$ and $\mathrm{r}\left(\mathrm{dp}, \mathrm{F}_{10.7}\right.$ and $\left.\mathrm{A}_{\mathrm{p}}\right)$ are lower and comparable with their corresponding coefficients $\mathrm{r}\left(\mathrm{ld}, \mathrm{A}_{\mathrm{p}}\right.$ and $\left.\mathrm{F}_{10.7}\right)$, r(ud, $\mathrm{A}_{\mathrm{p}}$ and $\left.\mathrm{F}_{10.7}\right)$ andr(dp, $A_{p}$ and $\left.F_{10.7}\right)$. It can be concluded that the correlation between $\mathrm{M}(3000) \mathrm{F} 2$ with $\mathrm{F}_{10.7}$ and $\mathrm{A}_{\mathrm{p}}$ are insignificant. 

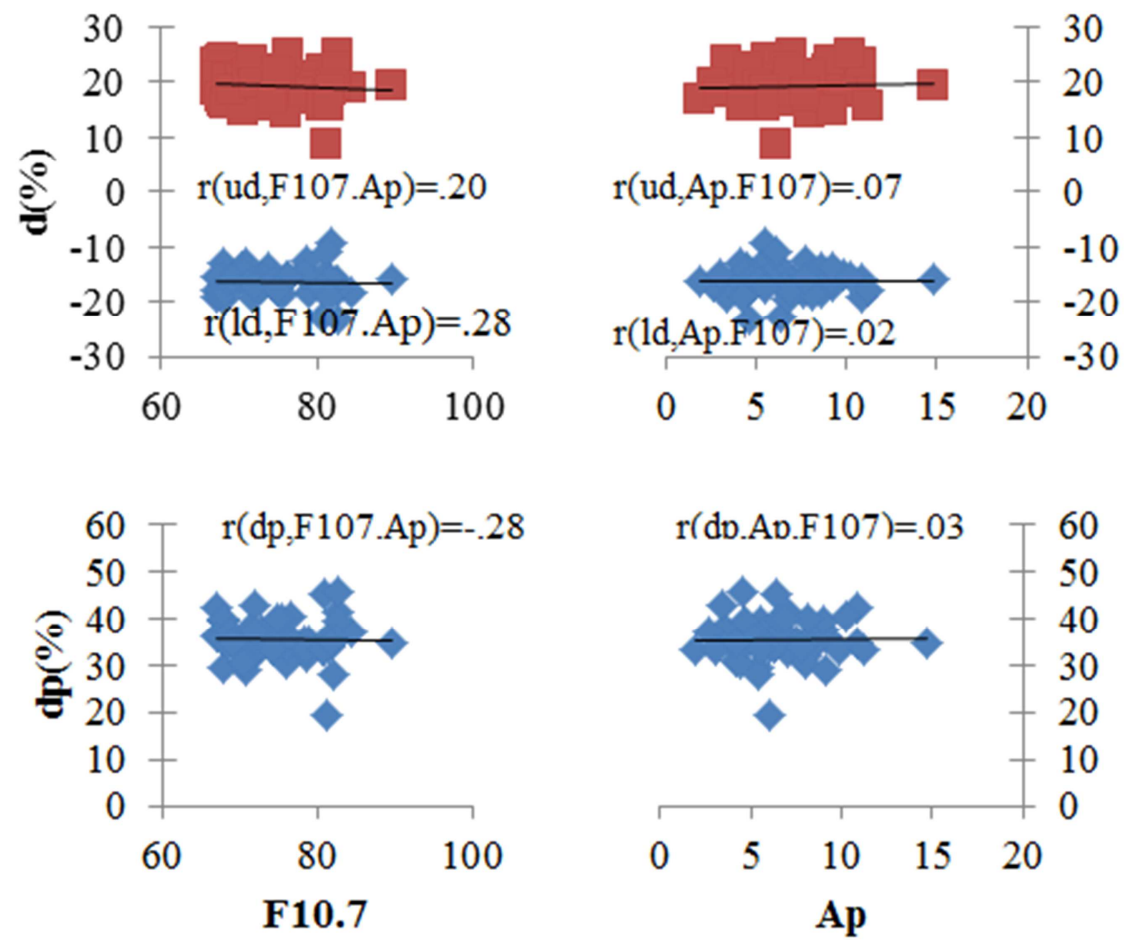

Figure 5. Dependence of monthly upper decileud\%, lower decileld\% and decile difference $d p \%$ of the F2 layer critical frequency (foF2) on solar activity (left part) on geomagnetic activity (right part) at the station Jicamarca during 2006 until 2010.The black lines are simple regression lines whereas the included values are partial correlation coefficients.
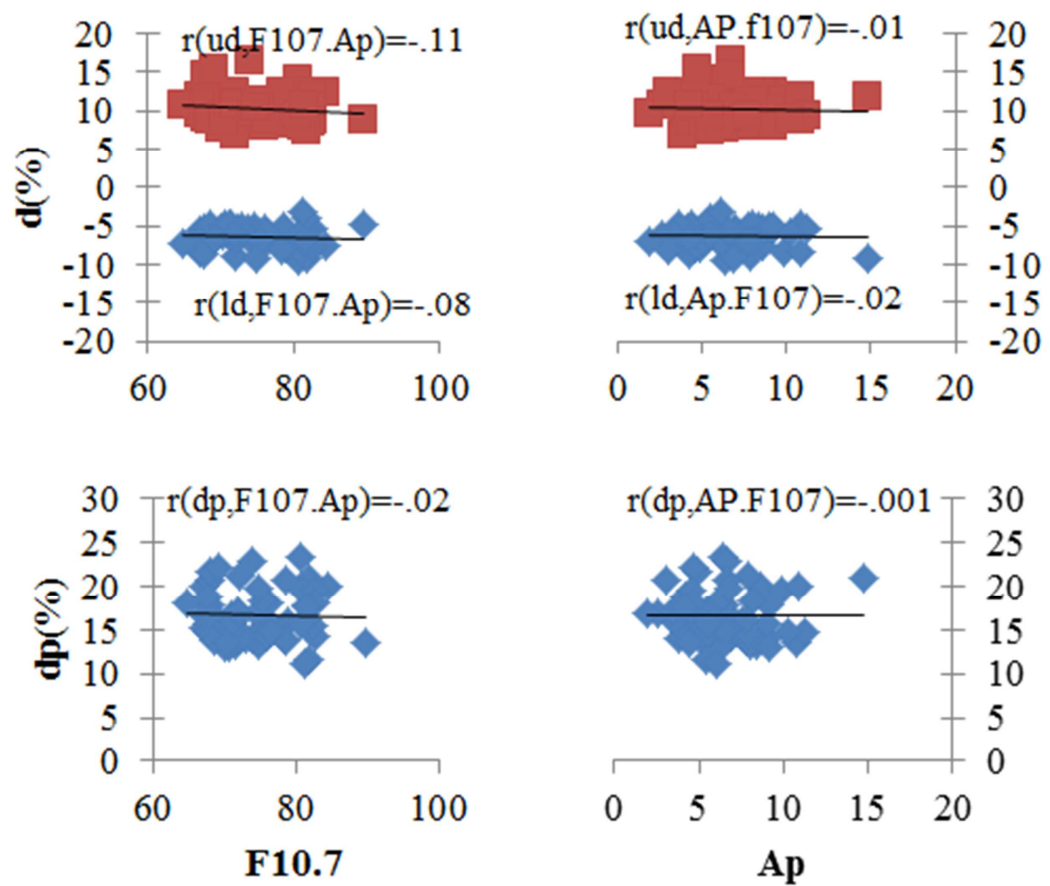

Figure 6. Dependence of monthly upper decileud\%, lower decileld\% and decile difference dp\% of the propagation parameter [M(3000)F2] on solar activity (left part) on geomagnetic activity (right part) at the station Jicamarca during 2006 until 2010.The black lines are simple regression lines whereas the included values are partial correlation coefficients.

\section{Discussion}

Many controlling factors, such as solar radiation, geomagnetic activity, and even seismic activity, may result in ionospheric day-to-day variability [19,20]. According to
Forbes et al. [21]ionospheric variability increases with magnetic activity at all latitudes and for both low and high frequency ranges, and the slopes of all curves increase with latitude. Thus the responsiveness of the ionosphere to increased magnetic activity increases as one progress from lower to higher latitudes. The authors did not consider 
variations of in the variabilities versus local time and season. The local time and seasonal variations in the ionospheric $\mathrm{F}$ layer variabilities are statistically obtained by Araujo-Pradere et al. [22] and Risbeth and Mendillo [19] by analyzing global ionosondes observations. Risbeth and Mendillo [19] suggested that the greater variabilitiesat night, especially in winter, is partly due to the lowerelectron density, partly due to the lack of the strong photochemical control that exists in the daytime $\mathrm{F}_{2}$-layer, but occurs largely because the auroral sources of magnetic activity become stronger and move to lower latitudes at night. This effect is enhanced in the winter when nights are long.

Recently, Adebesin [5] reported that annually night-time variability of $\mathrm{foF}_{2}$ is higher than daytime variation. The author revealed that an average pre-sunrise peak of $28 \%$ around 0300LT. The daytime values ranges from $8-13 \%$, while the post sunset peak recorded $23 \%$. The differences in the daytime/night-time observation were explained in part, to be due to the lower mean $(\mu)$ value during the night, which for comparable absolute variability give rise to higher variability percentage at night-time [11]. The two foF $\mathrm{F}_{2}$ peaks observed are ascribed to abrupt electron density gradients triggered by the onset and turn off of solar ionization, as well as the superposition of spread $\mathrm{F}$ on the background electron density [23].

Our results for the station Jicamarca is found to be similar to those reported by Adebesin [6]. However, the departures are observed during the sunspot minimum years 2007-2009 of solar cycle 23. Adewale et al. [24] also found that the variability of VTEC has large value during night-time especially post-midnight hours and post-sunset. Sethi et al. [25] showed that both the Dudeney [26] and Bilitza [27] formulations reveal more or less a similar diurnal trend of $\mathrm{h}_{\mathrm{m}} \mathrm{F}_{2}$ with higher value around midnight and lower during sunrise in all the seasons. They explained the variation of $\mathrm{h}_{\mathrm{m}} \mathrm{F}_{2}$ in terms of equatorial EXB drift as well as thermospheric neutral winds. The maximum values of $h_{m} F_{2}$ around midnight are caused by an increase of upward drifts produced by meridional winds in the neutral air $[28,29]$ while around sunrise hours, with the beginning of intensive ionization, the electron concentration near the $F_{2}$ peak increases at a rate which depends primarily upon the production rate, and thus the layer maximum shifts downwards due to rapid production of ionization in the lower F-region [30]. In the daytime as the temperature increases the concentration of atomic oxygen and loss coefficient which is proportional to the molecular components, both increase resulting in higher altitudes of layer maximum. In the evening as the rate of ion formation decreases a transitional period follows during which the height of layer maximum increases to its night-time value and this process is enhanced by a change in the direction of the thermospheric winds, since an upward drift causes an additional uplift of the layer. The drift rate increases towards midnight resulting in a rise in the $\mathrm{F}_{2}$ layer around midnight.

When comparing the results of Sethi et al. [25] it can be observed that the median values of $\mathrm{M}(3000) \mathrm{F}_{2}$ show in general quite opposite diurnal trend during all the seasons at all three stations. This is might be due to strong anticorrelation between $\mathrm{F}_{2}$-layer peak height $\left(\mathrm{h}_{\mathrm{m}} \mathrm{F}_{2}\right)$ and the propagation factor $\mathrm{M}(3000) \mathrm{F}_{2}$ [31]. Oyekola [15] found a strong anti-correlation between $\mathrm{M}(3000) \mathrm{F}_{2}$ and $\mathrm{Vz}$. valuesduring low solar activity period. The author also observed the semi-annual variation in the variability, $\sum$ of $\mathrm{M}(3000)] \mathrm{F}_{2}$ with maxima near the April and September equinox during low solar flux conditions.

The phenomenon of seasonal or semi-annual variation (anomaly or winter anomaly) has been discussed and explained by many researchers during past years. Torr and Torr [32] studying the winter anomaly by using noon monthly median values of $\mathrm{foF}_{2}$ for a chains of stations over the globe under different solar activity conditions, concluded that the winter anomaly is more pronounced in the northern hemisphere and the magnitude of the winter anomaly decrease with decreasing solar activity. The seasonal variation in the ionosphere of earth may occur due to electron density variation which might arises from the changes of the temperature, composition or both. Asymmetric heating of the two hemispheres can result in neutral constituents being transported from the summer to the winter hemisphere. As a result, an increase of the $\mathrm{O} / \mathrm{N}_{2}$ ratio caused by the convection of atomic oxygen is formed in the winter hemisphere [32].

A meridional component of neutral wind blows from the summer to the winter hemisphere which can reduce the crest value during summer solstice as it blows in an opposite direction to the plasma diffusion process originating from the magnetic equator. At the equinoxes meridional winds from equator blows pole-wards should result in a high ionization crest value. Based on this mechanism a seasonal effect on the crests should be expected with the crest maximum at the equinox and minimum in the summer [33-37].

Chandra et al. [38] have examined the day-to-day variability in the critical frequency of F-layer $\left(\mathrm{foF}_{2}\right)$ over Ahmedabad. They showed that while the daytime deviations are of same orders during different seasons the night-time, deviation are least during equinoxes. The day time values of $\mathrm{foF}_{2}$ are mainly controlled by the equatorial electrodynamics and the subsequent development of equatorial ionization anomaly the higher values during night-time seen to be due to the variability in the thermopheric neutral temperature and winds. However, from the seasonal and solar activity standpoint post-sunset September equinox maximum and June solstice maximum variability was observed at all the stations for all seasons (Akala et al. [17] .Our results are well compared with that observed at equatorial latitudes and described by Akala et al. [17].

It has been recognized for a long time that the geomagnetic activity reveals a semi-annual variation which is controlled by the solar wind and the response of the magnetosphere ionosphere system to the solar wind input. The major cause of the semi-annual variation of geomagnetic activity is usually attributed to an IMF effect [39]. Mill-ward et al. [40] using the coupled thermosphere ionosphere model (CTIP) showed that the offset of the geomagnetic axis from earth's 
spin axis is the cause of the semi-annual anomaly of noontime $\mathrm{NmF}_{2}$ in the South American sector.

Recently, Milich end Bremer [41] analyzed foF $\mathrm{F}_{2}$ using a modified ionosphereactivity data using a modified ionospheric activity index $\mathrm{AI}$ and showed that the quartile difference $\mathrm{dq}$ and standard deviation describing the variability of the AI data, have nearly identical seasonal variations with maxima near the equinoxes, a marked minimum in summer and enhanced values in winter. The authors found that most parts of these seasonal variations are closely connected with the mean geomagnetic activity variation, especially the equinoctial maxima and the minima in summer. More recently, Liu et al. [42] found remarkable seasonal anomaly over low latitude stations during low solar activity period. They also found a relative good Correlation between solar activity and monthly peak VTEC while low correlation was found between geomagnetic activity and it. Correia et al. [43] found that VTEC shows a clear semiannual anomaly with peaks during the equinoxes similar to what has been observed at all latitudes. They reported that a winter anomaly was not observed probably because it has the least chance to be observed in the South Pacific areas in the America Sector [44]. Long term and short term changes in daytime TEC near the crest of the equatorial anomaly region are mainly controlled by the equatorial electrojet strength $[45,46]$. Dabas et al. [47] concluded that the short as well as long-term variations in critical frequency of the F-layer $\left(\mathrm{foF}_{2}\right)$ are found to be mainly controlled by the equatorial electrojet (EEJ) variation. Since the photo-ionization rate is proportional to atomic oxygen $(\mathrm{O})$ and the loss rate is proportional to molecular nitrogen $\left(\mathrm{N}_{2}\right)$ and oxygen $\left(\mathrm{O}_{2}\right)$ a decrease in the mean molecular mass from down-welling through constant pressure surfaces would lead to increases in $\mathrm{N}_{\mathrm{m}} \mathrm{F}_{2}$ while an increase in the mean molecular mass due to upwelling results in $\mathrm{N}_{\mathrm{m}} \mathrm{F}_{2}$ decrease. A rise in $\mathrm{h}_{\mathrm{m}} \mathrm{F}_{2}$ to downward foF2 depletions are as a result of increase vertical drifts. Ionospheric plasma is raised by this drift beginning from the $F_{2}$-regions ofreduced loss due to equator-ward winds would also generate increases in $\mathrm{NmF}_{2}$ if they occur while production is still occurring. Similarly a drop in $\mathrm{hmF}_{2}$ due to pole-ward winds reduces $\mathrm{NmF}_{2}$ [48].

Consequently, ionospheric variability may also be attributed to the variability of other driving forces like tidal waves, equatorial zonal electric fields, which drives the equatorial electroject (EEJ) and the equatorial ionization anomalies especially at low latitude regions [49].

\section{Conclusions}

The diurnal observation revealed that foF2 is more vulnerable to variability during night than the daytime having two maxima during the day, a little before (after) the sunrise (sunset) between .20 and .40 (normally). The number of disturbed hours per month is higher during night-time hours than near noon. The variability is greater in winter and summer than Equinox. On a station to station comparison, the variability is noted to decrease for the stations situated just outside the anomaly crest. In view of M(3000)F2, the range of variation is normally within \pm .10 . Large deviations of $\mathrm{dM}(3000) \mathrm{F} 2$ are actually rare. It is also pointed out that the upper deciles of the M(3000)F2 variability have clear dependence on hour rather than lower deciles. There is no clear seasonal variation. However, daytime variability is maximum in summer and minimum in equinox while during night-time variability maximum in summer and minimum in winter. It is found that the influence of solar activity is greater than geomagnetic activity on the monthly variation of foF2. In contrast to foF2 the propagation parameter $\mathrm{M}(3000) \mathrm{F} 2$ does not show any clear picture.Furthermore for both parameters there are no any remarkable changes in dayto-day variability with geomagnetic activity during low solar activity period.

\section{References}

[1] E.V.Appleton,"Two anomalies in the ionosphere",Nature, vol. 157, 1946,pp. 691.doi: 10.1038/157691a0.

[2] R.A. Duncan, "The equatorial F-region of the ionosphere", J Atmos. Terr. Phys., vol. 18, 1960,pp. 89-100.

[3] N.B. HansonandR.J. Moffett, "Ionization transport effects in the equatorial F region", J. Geophys. Res., vol. 71, 1966, pp. 5559-5572.doi: 10.1029/JZ071i023p05559.

[4] D.N.Anderson,"A theoretical study of the ionospheric Fregion equatorial anomaly - I. Theory", Planet. Space Sci., vol. 21, no. 3, 1973, pp. 409-419.doi: 10.1016/0032-0633 (73)90040-8.

[5] B.O. Adebesin, " On the ionospheric variability of critical frequency along the equator anomaly trough ad plausible role of vertical EXB drift", J. Life physical sciences, vol. 5, no. 1, 2014,pp. 37-51.

[6] S.J.Adebiyi,I.A.Adimula, O.A.Oladipo, S.O.Ikubanni, B.O.Adebesin and B.W. Joshua, "GPS derived TEC and foF2 variability at an equatorial station and the performance of IRI model", Adv. Space Res., vol. 54, no. 4, 2014, pp. 565-575. doi: 10.1016/j.asr.2014.03.026.

[7] D.A. Gnabahou, F.Ouattara, E.Nanema andF.Zougmore, "foF2 diurnal variability at African equatorial stations: Dip equator secular displacement effect", International Journal of Geosciences, vol. 4, no. 8, 2013, pp. 1145-1150.doi: 10.4236/ijg.2013.48108.

[8] F.Ouattara, D.A.Gnabahou, and A.M. Christine,"Seasonal, diurnal, and solar cycle variations of electron density at two west Africa equatorial ionization anomaly stations", International Journal of Geophysics, vol. 2012, 640463, 2012.doi: 10.1155/2012/640463.

[9] M.M. Hoqueand A. Jakoswki, "A new global model for the ionospheric F2 peak height for radio wave propagation", Ann. Geophys., vol. 30, 2012, pp. 797-809.doi:10.5194/angeo-30797-2012.

[10] R.G.Ezquer, M.Mosert, R.Corbella, M.Erazu, S.M.Radicella, M. Cabrera and L. de la Zorda, "Day to day variability of ionospheric characteristics in the American Sector", Adv. Space Res. Vol. 34, no. 9, 2004, pp. 1887- 1893.doi: 10.1016/j.asr.2004.03.016. 
[11] O.Bilitza, O.K.Obrou, J.O.Adeniyi and O.Oladipo, "Variability of FoF2 in the equatorial ionosphere", Adv. Space Res., vol. 34, no. 9, 2004, pp. 1901-1906.doi: 10.1016/j.asr.2004.08.004.

[12] N.M. R. Al-Ubdaidi, "Daily mid-latitude F2-region critical frequency foF2 varaition with daily sunspot number R", Bull Astr. Soc. India, vol. 35, 2007,pp. 639-643.

[13] T.Atac, A.Ozguc, and R.Pektas, "The varaiblity of foF2 in different phases of solar cycle 23", J. Atmos. Terr. Physics, vol.71, no. 5, 2009, pp. 583-588.doi: 10.1016/j.astp.2009.01.004.

[14] D.S.V.V.D. Prasad, S.N.V.S.Prasad, J.Vara Prasad, N.S.M.P.Lathadeviand P.V.S. Rama Rao, "Diurnal and seasonal variations in h'f and foF2 over low and mid latitude stations - A comparative study", Indian journal of physics, vol. 84, no. 4, 2010, pp. 345-358.doi: 10.1007/s12648-010-0018-y.

[15] O.S.Oyekola, "Variation in the ionospheric propagating factor M(3000) F2 at Ouagadougou, Burkina Faso", Adv. Space Res.,vol. 46,no. 1, 2010,pp. 74-80.doi: 10.1016/j.asr.2010.02.017.

[16] H. Chandra, S. Sharma and S.W. Aung, "F-region variability over the anomaly crest region", Indian Journal of Radio and Space Physics, vol. 39, no. 5, 2010, pp. 302-307.

[17] A.O.Akala, E.O.Oyeymi, E.O.Somoye, A.B.Adeloye and A.O.Adewale, "Variability of $\mathrm{foF}_{2}$ in the African equatorial ionsphere", Adv. Space Res., vol. 45, no. 11, pp. 1311-1314, 2010.doi: 10.1016/j.asr.2010.01.003.

[18] S.S.Kouris, "The solar cycle variation of M(3000)F2 and its correlation with that of foF2", Ann. Geophys., vol. 41, no. 4, 1998, pp. 583-590.

[19] H.Risbeth and M.Mendillo, "Patterns of ionosphericvariability". J. Atmos. Terr. Phys., vol. 63, no. 15, 2001, pp. 1661-1680.doi: 10.1016/s1364-68266(01)00036-0.

[20] S.A.Pulinets, and J.Y. Liu, "lonospheric variability unrelated to solar and geomagnetic activity", Adv. Space Res., vol. 34, no. 9, 2004, pp. 1926-1933.doi:b10.1016/j.asr.2004.06.014.

[21] M.J. Forbes., E.S.Paol and X. Zhang, "Variability of the ionosphere, J. Atmos. Terr. Phys., vol. 62, no. 8, 2000, pp. 685-693.doi: 10.1016/S1364-6826(00)00029-8.

[22] E.A. Araujo-Pradere, T.J. Fuller Rowell, M.V. Codrescu, and D.Bilitza, "Characteristics of the ionospheric variability as a function of season, latitude, local time, and geomagnetic activity", Radio Sci., vol.40, no. 5, 2005,pp. RS5009.doi: 10.1029/2004RS003179.

[23] Y.T. Chouand C.C. Lee, "Ionospheric variability at Taiwan low latitude station: Comparison between observations and IRI 2001 model", Adv. Space Res., vol. 42, no. 18, 2008, pp. 673-681.doi: 10.1016/j.asr.2007.04.078.

[24] A.O.Adewlae, , E.O.Oyeyemi, P.J.Cilliers, L.A.Mckinnell, A.B. Adel, "Low solar activity variability and IRI 2007 predictability equatorial Africa GPS TEC", Adv. Space Res., vol.49, no. 2, 2012, pp. 316-326.doi: 10.1016/j.asr.2011.09.032

[25] N.K.Sethi, R.S.Dabas, and V.K. Vohra, "Diurnal and seasonal variations of $\mathrm{hmf} 2$ deduced from digital Ionosonde over New Delhi and its comparison with IRI 2001", Ann. Geophys., vol. 22,no. 2, 2004, pp.453-458.doi: 10.5194/angeo-22-453-2004.
[26] J.R.Dudeney, "The accuracy of simple methods for determining the height of the maximum electron concentration of the F2-layer form scaled ionospheric characteristics", J. Atmos. Terr. Phys.,vol. 45, pp. 629-640, 1983.doi: 10.1016/S0021-9169(83)80080-4.

[27] D. Bilitza and International Reference Ionosphere National Space Science Data Center, "Report 90-22", Greenbelt, Maryland, USA, 1990.

[28] W.B. Hanson, and T.N.L. Patterson, "The maintenance of night time F-layer", Planet. Space Sci., vol. 12, no. 10, 1964,pp. 979-997.doi: 10.1016/0032-0633(64)90112-6.

[29] H. Kohl and J.W. King, "Atmospheric winds between 100 and $700 \mathrm{~km}$ and their effects on the ionosphere" J. Atmos. Terr. Phys., vol. 29, no. 9, 1967, pp. 1045-1062.doi: 10.1016/00219169(67)90139-0.

[30] H.Risbeth, and O.K.Garriot, "Introduction to ionospheric physics", $10^{\text {th }}$ ed. Amsterdam: Academic press, 1969, pp. 331.

[31] T. Shimazaki, "Wolrd-wide daily variations in the height of the maximum electron density of the ionospheric F2-layer", J. Radio Res. Labs., vol. 2, no. 7, 1955,pp. 85-97.

[32] M.R.Torr and D.G.Torr,"The seasonal behaviour of the $F_{2}-$ layer of the ionosphere",Atmos. Solar-Terr. Phys., vol. 35, no. 12,1973, pp. 2237-2251.

[33] E.N.Bramley and M. Young,"Winds and electromagnetic drifts in equatorial F2-region", J. Atmos. Terr. Phys., vol.30, 1968, pp. 99-111.

[34] R.J.Stening, "Review Paper: modelling the low latitude F region”, J. Atmos. Terr. Phys., vol. 54, 1992, pp. 1378-1412.

[35] C.C.Wu, C.D. Fry, J.-Y. Liu, K.Liou and C.-L. Tseng, “Annual TEC variation in the equatorial anomaly region during the solar minium: September 1996-August 1997’. J. Atmos. Terr. Phys. Vol. 66, no. 3-4, 2004, pp. 199-207.doi: 10.1016/j.astp.2003.09.017.

[36] C.C. Wu, K.Liou, S.-J. Shan and C.-L. Tseng, "Variaton of ionospheric total electron content in Taiwan region of the equatorial anomaly from 1994 to 2003". Adv. space Res., vol. 41, no. 4, 2008, pp. 611-616.doi: 10.1016/j.asr.2007.06.013.

[37] P.K.Bhuyan and R.R. Borah, "TEC derived from GPS network in india comparison with the IRI", Adv. Space Res., vol. 39, no. 5, 2007, pp. 830-840, 2007.doi: 10.1016/j./asr.2006.12.042.

[38] H. Chandra, S. Sharma and S.W. Aung, "Day to day variability in the critical frequency of F2 layer over the anomaly crest region, Ahmedabad", J. Ind. Geophys.Union, vol. 13, no. 4, 2009, pp. 217-226.

[39] C.T. Russell, and R.L.Mcpherron, "Semiannual variation of geomagnetic activity”, J. Geophys. Res., vol. 78, no. 1, 1973, pp. 92-108.

[40] G.H.Millward, H.Risbeth,T.J. Fuller-Rowell, A.D.Aylward, S.Quegan, and R.J.Moffert, "Ionospheric F2 layer seasonal and semiannual variations", J. Geophys. Res.,vol. 101, no. A3, 1996, pp. 5149-5156.doi: 10.1029/95JA03343.

[41] J. Mielich and J. Bremer, "A modified index for the description of the ionospheric short and long term activity", Ann. Geophys., vol. 28, 2010, pp. 2227-2236.doi: 10.5194/angeo-28-2227-2010. 
[42] G. Liu, W. Huang, J. Gong and H. Shen, "Seasonal variability of GPS-VTEC and model during low solar activity period (2006-2007) near the equatorial ionization anomaly crest location in Chinese zone", Adv. Space Res., vol. 51, no.3, 2013,pp. 366-376.doi: 10.1016/j.asr.2012.09.002.

[43] E.Correia, A.J. Paz, and M.A.Gende,"Characterization of GPS total electron content (GPS-TEC) in Antarctica from 2004 to 2011”, Ann. Geophys., vol. 56, no. 2, 2013,pp. RO217.doi: $10.4401 /$ ag-6223

[44] Zhao, B., Wan, W., Liu, L., Mao, T., Ren, Z., Wang, M. and Christensen, A.B., Features of annual and semiannual variations derived from the global inospheric maps of total electron content, Ann. Geophys.,Vol. 25, no. 12, 2008, pp. 2513-2527.

[45] R.S.Dabas, P.K.Bhuyan, T.R. Tyagi, R.K.Bharadwaj, J.B.Lal, "Day to day changes in ionospheric electron content at low latitudes", Radio Sci., vol. 19, no. 3, 1984,pp.746-749.doi: 10.1029/RS019i003p00749.
[46] P.Aravindan, K.N.Iyer, "Day to day variability in ionospheric electron content at low latitudes", Planet Space Sci., vol. 38, no. 6,1990, pp. 743-750.doi: 10.1016/0032-0633(90)90033-M.

[47] R.S.Dabas, N. Sharma, M.G.K. Pillai and A.K.Gwal, "Day to day variability of qautorial and low latitude F-region ionosphere in the Indian zone", J. Atmos. Terr. Phys., vol. 68, no. 11, 2006, pp. 1269-1277.doi: 10.1016/j.astp.2006.03.009.

[48] B.O.Adebesin, J.O.Adeniyi, I.A.Adimula, B.W.Reinisch and Yumoto, K., " $F_{2}$ layer characteristics and electrojet strength over an equatorial station", Adv. Space Res., vol.52, no. 5, 2013a, pp. 791-800.doi: 10.1016./j.asr.2013.05.025.

[49] B.O.Adebesin, J.O.Adeniyi, I.A.Adimula, and, B.W.Renisch, "Equatorial vertical plasma drift velocities and electron densities inferred from ground-based ionosonde measurements during low solaractivity", J. Atmos. Terr. Phys., vol. 97, 2013b, pp. 58-64.doi: 10.1016/j.astp.2013.02.010. 